\title{
Notes on Kaszabjbaloghia with the description of a new species from Ecuador (Acari: Mesostigmata: Uropodidae)
}

\author{
Jenõ Kontschán
}

Systematic Zoology Research Group, Hungarian Academy of Sciences, Department of Zoology, Hungarian Natural History Museum. H-1088 Budapest, Baross u. 13. Hungary. E-mail: kontscha@zool.nhmus.hu

\begin{abstract}
Kaszabjbaloghia Hirschmann, 1973, distributed in South-America, is characterized by the following combination of characters: reduced marginal shield, posteromarginal setae placed on membranous cuticle on the dorsal idiosoma, linguliform genital shield in females, oval or egg-like genital shield bearing one pair needle-like setae in males, and the characteristic shape of peritremes. In this contribution, I provide short redescriptions of the known species of Kaszabjbaloghia and describe a new species, K. ecuadorica sp. nov., from Ecuador. The new species is similar to K. kaszabi Hirschmann, 1973, but differs from the latter in the ornamentation of genital shield of the female and the number of sternal cavities. Additionally, we transfer K. hirschmanni Hiramatsu, 1978 to Hutufeideria Hirschmann \& Hirmatsu, 1977 (as Hutufeideria hirschmanni (Hiramatsu, 1978) comb. nov.) on the basis of the following: setation of dorsal shield, ornamentation of caudal part of the dorsal shield, shape of hypostomal setae, shape of internal malae and setation of the palp. An identification key to the species of Kaszabjbaloghia is also provided. Original illustrations and scanning micrographs are provided for all species.
\end{abstract}

KEY WORDS. Acarology; taxonomy; Uropodina.

Werner Hirschmann described Kaszabjbaloghiafrom Prof. János Balogh's South American unsorted Berlese collections (Hirschmann 1973a). The new genus was named after two Hungarian zoologists (Prof. János Balogh, acarologist, and Prof. Zoltán Kaszab, beetle-specialist). In the same year, HirschmanN (1973b) described five new species of Kaszabjbaloghia from Ecuador, Peru and Brazil. Some years later, Hiramatsu (1978) described a new Kaszabjbaloghia species from Australia.

Originally, Hirschmann (1973a) placed the new genus in the Uropodidae, but later he erected a new family, Kaszabjbaloghiidae Hirschmann, 1979, for Kaszabjbaloghia (HiRschmanN 1979). His new family, however, was not mentioned subsequently in the literature, neither by HiRschmann (1993) nor by his coworkers in their catalogs (WISNIEWSKI 1993a, b, WISNIEWSKI \& HiRSCHMANN 1993).

Recently, VÁzquez \& Klompen (2007) listed several Uropodina species from Central America, including an unidentified Kaszabjbaloghia species from Mexico. Also recently, Hungarian researchers have published a series of papers on tropical soil zoology (Csuzdi \& Tondoh 2007, KonTsChán 2007, 2008, MaHunKa $2007,2008)$. The present paper on Kaszabjbaloghia is part of these studies. Herein we provide a diagnosis for the genus and for all known species of Kaszabjbaloghia . Additionally, we describe K. ecuadorica sp. nov., from Ecuador.

\section{MATERIAL AND METHODS}

Syntypes of all known Kaszabjbaloghia species were investigated from the Soil Zoology Collections of the Hungarian Natural History Museum, Budapest. These specimens were stored on slides with Hirschmann's handwriting.

Newly collected specimens were cleared in lactic acid and drawings were made with a camera lucida. Scanning micrographs were taken in the Hungarian Natural History Museum with a HITACHI SN 2600 scanning electron microscope. The specimens are stored in alcohol and are deposited in the Soil Zoology Collections of the Hungarian Natural History Museum. The names of localities that are new distribution records follow ZICSI \& CsUZDI (2008). All measurements are given in micrometers $(\mu \mathrm{m})$.

\section{TAXONOMY}

\section{Kaszabjbaloghia Hirschmann, 1973}

Kaszabjbaloghia Hirschmann, 1973a: 103; Hirschmann, 1979: 60; 1993: 293 and 328; Wisniewski, 1993b: 383; Wisniewski \& Hirschmann, 1993: 32.

Type species: Kaszabjbaloghia kaszabi Hirschmann, 1973, by original designation.

Diagnosis. Idiosoma oval, posterior margin rounded. Dorsal and marginal shields do not fuse. Marginal shield reduced, 
posterior margin reach level of posterior margin of dorsal shield. Marginal setae can be found on small platelets on membranous cuticle. Female with linguliform genital shield, male with oval or egg-like genital shield bearing one pair of long setae. Peritreme with two characteristic forms, one type is tree-like, the other is hook-shaped with several branches. Tritosternum with narrow basis and trifurcated laciniae. Hypostomal setae h1 subdivided into three branches, central branch smooth, lateral branches with short hairs on their margins. Setae h2 short with serrated margin, h3 with Y-form apical part, h4 with short hairs on its apical part. Corniculi horn-like, internal malae long and with short hairs on their margins. Chelicerae with several teeth on digitus fixus and with some big teeth on digitus mobilis. Epistome serrated on basal part and with short hairs on its apical part. Palp trochanter with serrated setae, other setae smooth and simple. All setae of legs serrated or smooth, leg I without ambulacral claw.

Distribution. Central and South America.

Systematic notes. HiRSCHMANN (1973a) placed this genus in the Uropodidae. Later, a new family, the Kaszabjbaloghiidae Hirschmann, 1979, was erected for it. The presence of several unique characters in this genus (e.g., shape of peritreme, setae on the genital shield of male, setae of palp trochanter and hypostome) supports Hirschmann's (1979) concept of the Kaszabjbaloghiidae. Currently, the systematics of the Uropodina at family and genus levels has several problems, such as the lack of clear diagnoses. As revisions are needed for all included families, we have followed Hirschmann's (1993) most recent classification, and treated Kaszabjbaloghia as a genus of Uropodidae. This treatment contrasts with VÁzquez \& KLOMPEN (2007), who treated this genus as Kaszabjbaloghiidae and mentioned several other families of HiRsCHMANN's (1979) system. However, the limits of several families and genera in Hirschmann's (1979) system are very questionable.

Remarks. Hiramatsu (1978) described a new Kaszabjbaloghia species from Australia, K. hirschmanni Hiramatsu, 1978. I have investigated Hiramatsu's (1978) description and studied the syntypes that are deposited in the Soil Zoology Collections of the Hungarian Natural History Museum. Based on careful analysis, I have concluded that $K$. hirschmanni does not belong to Kaszabjbaloghia because it lacks the most important diagnostic characters of the genus (shape of peritreme, setae on male genital shield, etc.). I am convinced that this species belongs to Hutufeideria Hirschmann \& Hiramatsu, 1977, so I propose a new combination Hutufeideria hirschmanni (Hiramatsu, 1978) comb. nov. My conclusions are based on the following characters: setation of dorsal shield, ornamentation of caudal part of dorsal shield, shape of hypostomal setae, shape of internal malae and setation of palp.

\section{Kaszabjbaloghia mahunkai Hirschmann, 1973}

Figs 1-3

Kaszabjbaloghia mahunkai Hirschmann, 1973b: 109-110; Wisniewski \& Hirschmann, 1993: 32; Wisniewski, 1993a: 239; 1993b: 383.
Material examined. Syntype: One male on slide Qb-B 13b: "South-America, 1971, QB-B-13, Quito-Baeza-line, Ecuador, leg. J. Balogh".

New specimens. Ecuador, Prov. Pichincha: Rio Guajalito, Las Palmeras (1850 $\mathrm{m}$ a.s.l. Real primary forest, litter and upper soil level, from soil and roots), one male, 18.IV.1989, Cs. Csuzdi \& A. Zicsi leg., ECU 1989 B55. EcuAdor, Prov. Pichincha: Rio Guajalito, Las Palmeras (1850 m a.s.l. Real primary forest, litter and upper soil level, loose moss, hanging from trees), one male, 18.IV.1989, Cs. Csuzdi \& A. Zicsi leg., ECU 1989 B56.

Short description. Dorsal shield covered by alveolar ornamentation. All dorsal and marginal setae phylliform. Well sclerotized half-ring can be found on caudal region of dorsal shield (Fig. 1). Peritreme tree-like (Fig. 3). Sternal and ventral shields with alveolar ornamentation, ventral setae phylliform. Male egg-like genital shield with one pair of long setae (Fig. 2).

Distribution. Ecuador.

\section{Kaszabjbaloghia mahunkaisimilis Hirschmann, 1973 Figs 4-6}

Kaszabjbaloghia mahunkaisimilis Hirschmann, 1973b: 109-110; Wisniewski \& Hirschmann, 1993: 32; Wisniewski, 1993a: 240; 1993b: 383.

Material examined. Syntype: One female on slide LP-B 15: "South-America, 1971, LP-B-15, Lima Pucallpa-line, Peru, leg. J. Balogh".

Short description. Dorsal shield with alveolar ornamentation. All dorsal and marginal setae phylliform. Well sclerotized ring can be found on caudal region of dorsal shield, posterior part of ring strongly more sclerotized than anterior part (Fig. 4). Peritreme tree-like (Fig. 6). Sternal and ventral shields without ornamentation, margins of sternal and ventral setae serrated. Female linguliform genital shield without anterior process and with maculate pattern on basal part (Fig. 5).

Distribution. Peru.

\section{Kaszabjbaloghia kaszabi Hirschmann, 1973} Figs 7-8

Kaszabjbaloghia kaszabi Hirschmann, 1973b: 108; Hirschmann, 1979: 60; Wisniewski \& Hirschmann, 1993: 32; Wisniewski, 1993a: 239; 1993b: 383.

Material examined. Syntype: one female on slide QB-B 23a. "South-America, 1971, QB-B-23, QB-B-24, Quito-Baezaline, Ecuador, leg. J. Balogh".

New specimens. Ecuador, Prov. Pichincha: Rio Guajalito, Las Palmeras (1850 $\mathrm{m}$ a.s.l. Real primary forest, litter and upper soil level, from soil and roots), two females, 18.IV.1989, Cs. Csuzdi \& A. Zicsi leg., ECU 1989 B55. Ecuador, Prov. Pichincha: Rio Guajalito, Las Palmeras (1850 m a.s.l. Real primary forest, litter and upper soil level, from moss from the riverside - vertical soil-wall), noe female, 18.IV.1989, Cs. Csuzdi \& A. Zicsi leg., ECU 1989 B59. 

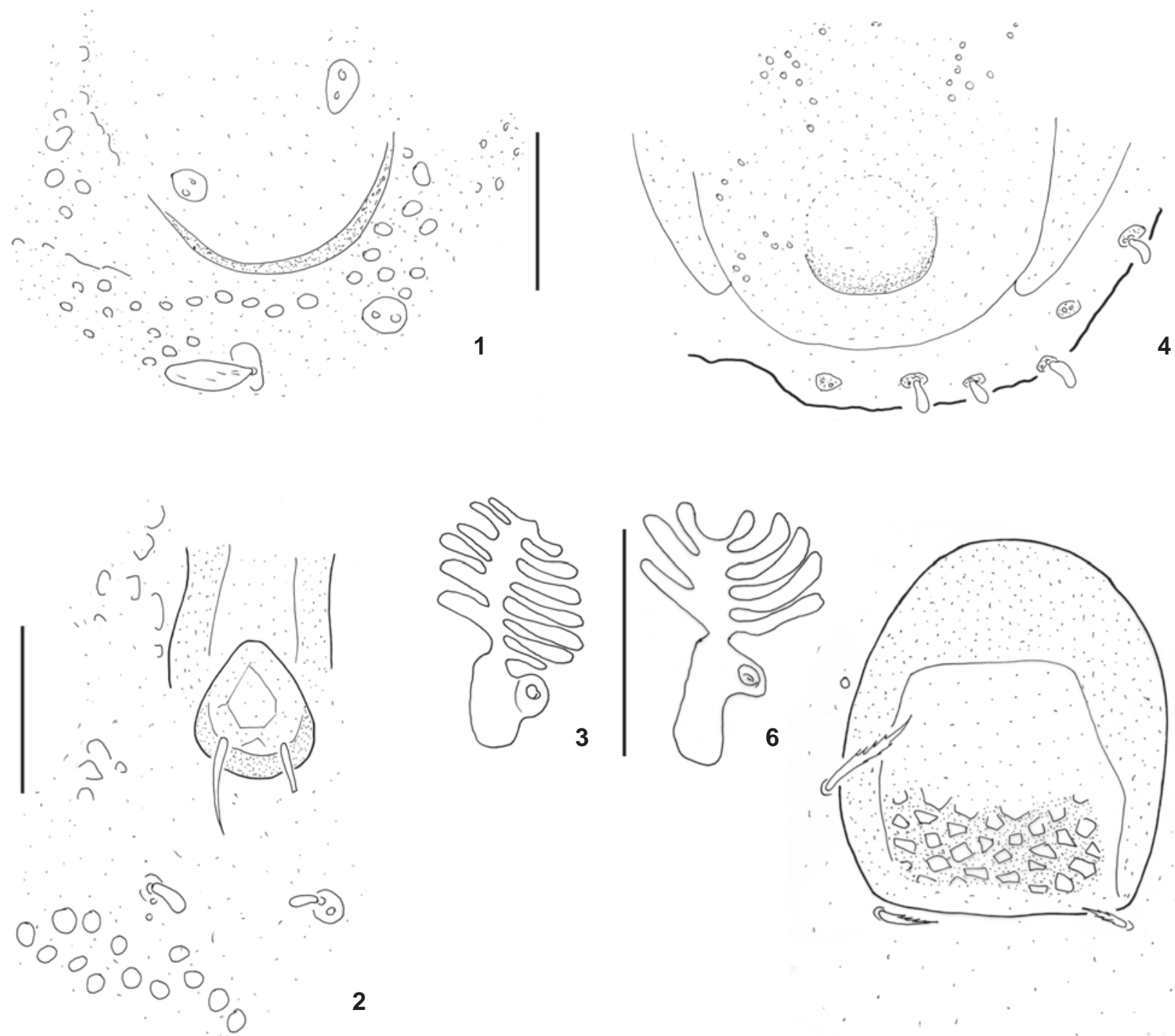

2

Figures 1-6. The known Kaszabjbaloghia species. (1-3) K. mahunkai, male: (1) setae on dorsum; (2) genital region; (3) peritreme. (4-6) K. mahunkaisimilis, female: (4) setae on dorsum; (5) genital region; (6) peritreme. Scale bar: $100 \mu \mathrm{m}$.

Short description. Dorsal and marginal shields with alveolar ornamentation. All dorsal and marginal setae long and phylliform (Fig. 7). Peritreme hook-shaped with several branches. Sternal shield without ornamentation, only on lateral and caudal parts of ventral shield can be found alveolar ornamentation. Sternal setae smooth and needle-like, ventral setae narrow phylliform. Female linguliform genital shield without anterior process and with maculate pattern (Fig. 8).

Distribution. Ecuador.

\section{Kaszabjbaloghia kaszabisimilis Hirschmann, 1973}

Fig. 9

Kaszabjbaloghia kaszabisimilis Hirschmann, 1973b: 108-109; Wisniewski \& Hirschmann, 1993: 32; Wisniewski, 1993a: 240; 1993b: 383.

Material examined. Syntype: one male on slide LP-B 8b: "South-America, 1971, LP-B-8, Lima Pucallpa-line, Peru, leg. J. Balogh." 

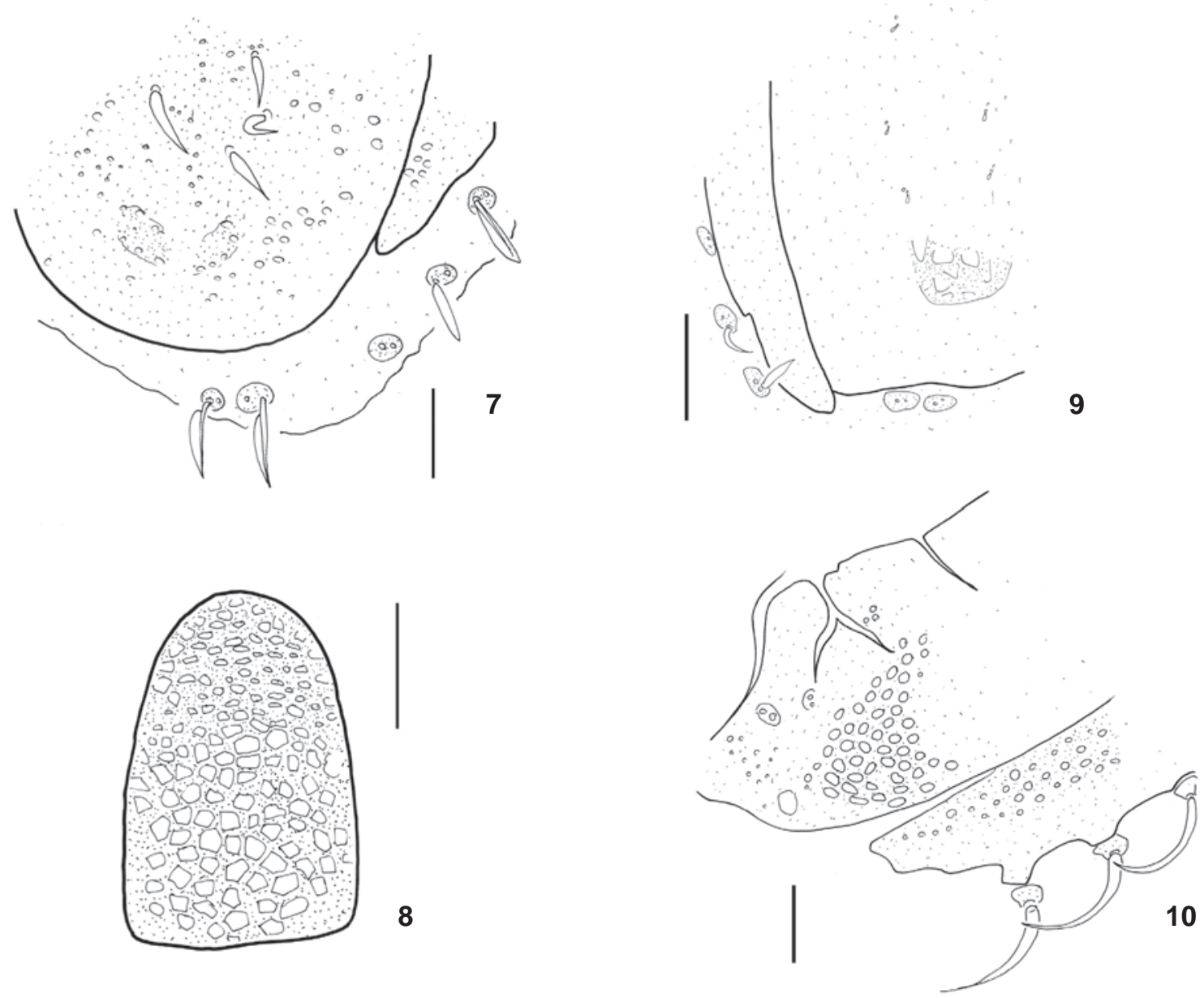

Figures 7-10. The known Kaszabjbaloghia species. (7-8) K. kaszabi: (7) setae on dorsum; (8) genital shield of female. (9) setae on dorsum of K. kaszabisimilis. (10) long marginal setae of K. zicsii. Scale bar: $100 \mu \mathrm{m}$.

Short description. Dorsal and marginal shields with several small alveolar ornamentations. All dorsal setae short and phylliform, marginal setae long, narrow and phylliform (Fig. 9). Hook-shaped peritreme with several branches. Sternal shield with several small alveolar ornamentations, ventral shield with pattern. Sternal and ventral setae smooth and needle-like. Male egg-like genital shield with one pair of long setae.

Distribution. Peru.

\section{Kaszabjbaloghia zicsii Hirschmann, 1973 Fig. 10}

Kaszabjbaloghia zicsii Hirschmann, 1973b: 110; Wisniewski \& Hirschmann, 1993: 32; Wisniewski, 1993a: 232; 1993b: 383.

Material examined. Syntype: one female on slide BRB22c: "Brazil, Fazenda Agua Azul, Maranhão State, Serra do Gurupi, NW von Imperatriz, 09.09.1967. leg. J. Balogh."
Short description. Dorsal and marginal shields bear alveolar ornamentation. All dorsal setae short and phylliform, marginal setae long and setiform, on caudal region longer than others (Fig. 10). Sternal shield without ornamentation, ventral shield with pattern on lateral and caudal parts. Sternal and ventral setae smooth and needle-like. Female linguliform genital shield without anterior process and without ornamentation.

Distribution. Brazil.

\section{Kaszabjbaloghia ecuadorica sp. nov.}

Figs 11-23

Description. Female. Length of idiosoma 890-920 $\mu \mathrm{m}$, width 460-510 $\mu \mathrm{m}(\mathrm{n}=3)$. Shape oval, posterior margin rounded.

Dorsal idiosoma (Figs 11 and 16). Setae on dorsal shield smooth, long and setiform, marginal setae long and phylliform (Fig. 17). Three pairs of caudal setae can be found on small 

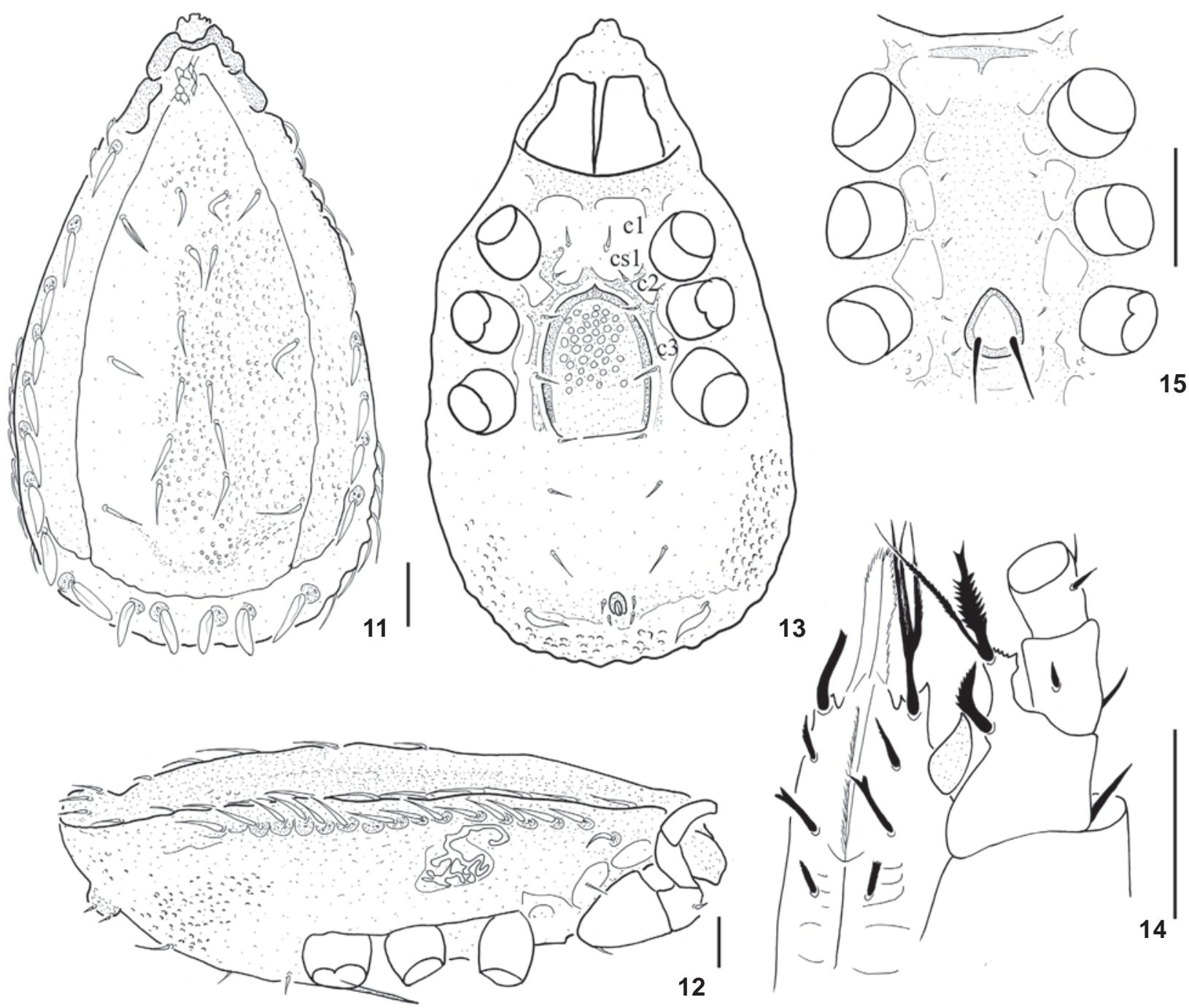

Figures 11-15. Kaszabjbaloghia ecuadorica sp. nov.: (11) dorsal view; (12) lateral view; (13) ventral view; (14) ventral view of gnathosoma, female; (15) sternal region, male. Scale bar: $100 \mu \mathrm{m}$.

platelets on membranous cuticle. Dorsal and marginal shields with small alveolar ornamentation.

Ventral idiosoma (Figs 13 and 20). Sternal shield without ornamentation, only on lateral and caudal parts of ventral shields can be seen alveolar ornamentation. Six cavities can be found on sternal shield. First pair large (and subdivided into deep (c1) and shallow (cs1) parts) and placed between coxae II, second pair (c2) small and placed near posterior margin of coxae II, third (c3) localized near margins of coxae III. Sternal setae short and needle-like, St 1 can be found in cavity cs1, St 2 placed near anterior margin of genital shield, St3 near anterior margin of coxae III, St4 near anterior margin of coxae IV. St5 can be seen near basal part of genital shield. Genital shield linguliform, with alveolar ornamentation on apical region and with spine-like anterior process (Fig. 21). Two pairs of ventral needle-like setae and one pair of ventral phylliform setae on caudal region. Adanal setae two times shorter than ventral setae and needle-like. Postanal setae absent.

Stigmata situated between coxae II and III. Peritreme hook-shaped with several branches (Figs 12 and 18-19).

Legs with serrated setae (Fig. 22).

Gnathosoma (Fig. 14). Corniculi, internal malae, epistome, hypostomal setae and palp setae typical for genus. Chelicerae not clearly visible.

Male. Length of idiosoma 830-880 $\mu \mathrm{m}$, width 480-510 $\mu \mathrm{m}(\mathrm{n}=8)$. Shape oval, posterior margin rounded. 

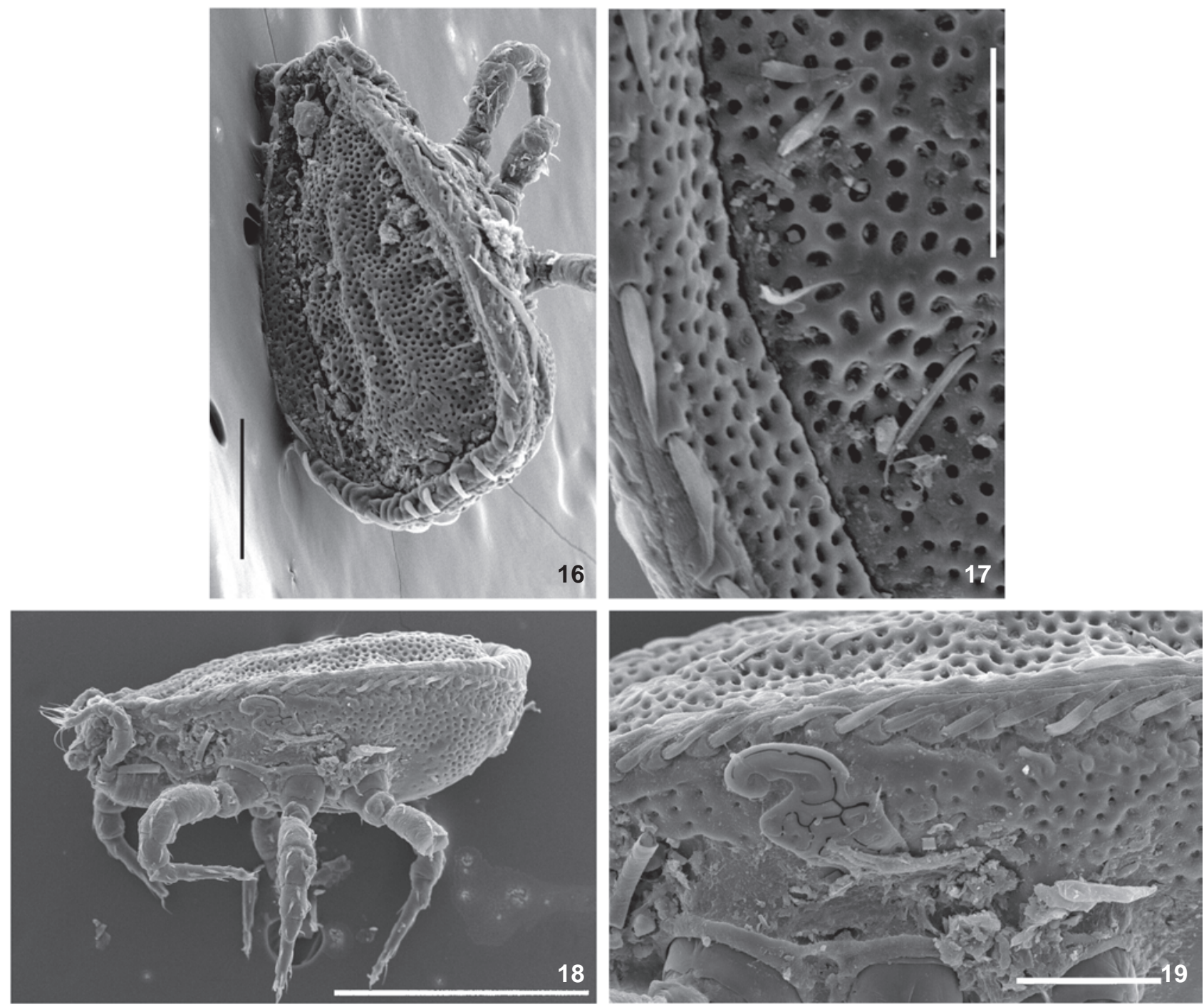

Figures 16-19. Scanning micrographs of Kaszabjbaloghia ecuadorica sp. nov.: (16) dorsal view; (17) dorsal setae and ornamentation; (18) lateral view; (19) peritreme. Scale bar: (16) $250 \mu \mathrm{m}$, (17 and 19) $100 \mu \mathrm{m},(18) 500 \mu \mathrm{m}$.

Dorsal idiosoma. Ornamentation and chaetotaxy of dorsal shield as in female.

Ventral idiosoma (Figs 15 and 23). Sternal shield without ornamentation, only on lateral and caudal parts of ventral shields can be seen alveolar ornamentation. Eight cavities can be found on sternal shield. First pair large (c1) and second pair small (cs1), placed between coxae II, second pair (c2) small and placed near margin of coxae III, third (c3) localized between coxae III and IV. Sternal setae short and needle-like. Genital shield egg-like and with two long needle-like setae. Ventral and adanal setae and peritreme as in female.

Gnathosoma. Similar to female.

Nymphs and larvae unknown.
Taxonomic summary. Holotype. Ecuador, Prov. Pichincha (about $71 \mathrm{~km}$ from Quito to Santo Domingo, from moss from lakeshore leaving the waterfall), female. 24.IV.1988, Cs. Csuzdi \& A. Zicsi leg., ECU.B.15. Paratypes. Ecuador, Prov. Pichincha (about $71 \mathrm{~km}$ from Quito to Santo Domingo, from moss from lakeshore leaving the waterfall), two females and four males, 24.IV.1988, Cs. Csuzdi \& A. Zicsi leg., ECU.B.15. Ecuador, Prov. Pichincha: (about $71 \mathrm{~km}$ from Quito to Santo Domingo, from leaf litter), two males, 24.IV.1988, Cs. Csuzdi \& A. Zicsi leg., ECU.B.16; Ecuador, Prov. Pichincha: (between Quito and Santo Domingo, about $1 \mathrm{~km}$ from the church, from moss from the neighbourhood of a rapid), two males, 21.IV.1988, Cs. Csuzdi \& A. Zicsi leg., ECU.B.4. 

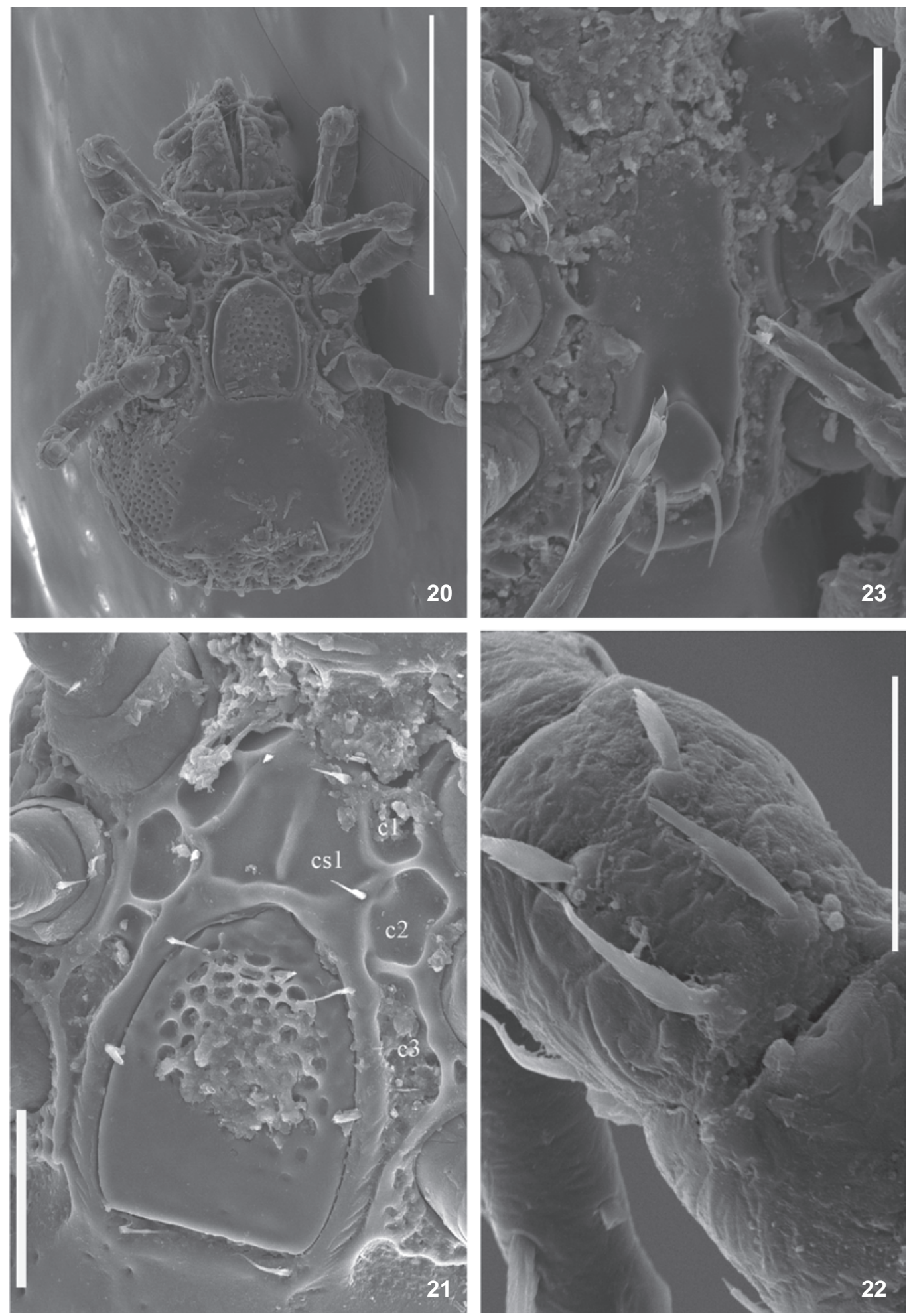

Figures 20-23. Scanning micrographs of Kaszabjbaloghia ecuadorica sp. nov.: (20) ventral view; (21) genital shield of female; (22) setae on leg IV; (23) genital shield of male. Scale bar: (20) $250 \mu \mathrm{m},(21-23) 100 \mu \mathrm{m}$. 
Etymology. The name of the new species refers to the country (Ecuador) where the specimens herein described were collected.

Remarks. The new species is similar to K. kaszabi. The most important differences are summarized in table I.

Table I. The most important differences between Kaszabjbaloghia kaszabi and K. ecuadorica.

\begin{tabular}{lcc}
\hline \multicolumn{1}{c}{ Structures } & K. kaszabi & K. ecuadorica \\
\hline $\begin{array}{l}\text { Ornamentation on genital shield } \\
\text { of female }\end{array}$ & entire & anterior \\
$\begin{array}{l}\text { Ornamentation type of genital } \\
\text { shield of female }\end{array}$ & maculate & alveolar \\
Large cavity between coxae II & absent & present \\
\hline
\end{tabular}

\section{Key to Kaszabjbaloghia species}

1. Long marginal setae on caudal part present (Fig. 10) .......... K. zicsii

- Long marginal setae on caudal part absent . .. 2

2. Peritreme tree-like (Figs 3 and 6) 3

- Peritreme hook-shaped with several branches (Fig. 12) .... 4

3. Ornamentation on ventral shield and on caudal region of dorsal shield present, sternal and ventral setae smooth (Figs 1 and 2) K. mahunkai

- Ornamentation on ventral shield and on caudal region of dorsal shield absent, sternal and ventral setae serrated (Figs 4 and 5) K. mahunkaisimilis

4. Dorsal setae short K. kaszabisimilis

- Dorsal setae long .. 5

5. Whole genital shield of female covered by maculate ornamentation K. kaszabi

- Apical part of genital shield of female covered by alveolar ornamentation K. ecuadorica

\section{LITERATURE CITED}

Csuzd, Cs. \& J.E. TondoH. 2007. New and little known earthworm species from Ivory Coast (Oligochaeta: Acanthodrilidae: Benhamiinae and Eudrilidae). Journal of Natural History 41: 2551-2567.

Hiramatsu, N. 1978. Gangsystematik der Parasitiformes Teil 296. Teilgange einer neuen Kaszabjbaloghia-Art aus Australien (Uropodini, Uropodinae). Acarologie. Schriftenreihe für Vergleichende Milbenkunde 24: 109-111.

Hirschmann, W. 1973a. Gangsystematik der Parasitiformes Teil
161. Die Gattungen Baloghjkaszabia und Kaszabjbaloghia nova genera (Uropodini, Uropodinae). Acarologie Schriftenreihe für Vergleichende Milbenkunde 19: 103-105.

Hirschmann, W. 1973b. Gangsystematik der Parasitiformes Teil 163. Stadien von 5 neuen Kaszabjbaloghia-Arten (Uropodini, Uropodinae). Acarologie Schriftenreihe für Vergleichende Milbenkunde 19: 107-110.

Hirschmann, W. 1979. Stadiensystematik der Parasitiformes Teil 1. Stadienfamilien und Stadiengattungen der Atrichopygidiina, erstellt im Vergleich zum Gangsystem Hirschmann, 1979. Acarologie Schriftenreihe für Vergleichende Milbenkunde 26: 57-68.

Hirschmann, W. 1993. Gangsystematik der Parasitiformes Teil 550. Bestimmungstabellen der Uropodiden der Erde, Atlas der Ganggattungen der Atrichopygiina. Acarologie Schriftenreihe für Vergleichende Milbenkunde 40: 292-370.

KonTSCHÁn, J. 2007. Uropodina mites (Acari: Mesostigmata) from Venezuela, with descriptions of four new species. Acta Zoologica Academiae Scientiarum Hungaricae 53 (4): 335346.

Kontschán, J. 2008. Trigonuropoda (Baloghiatrigon) dominicana sp. nov. from the Dominican Republic, with notes on the subgenus Baloghiatrigon Hirschmann, 1979 (Acari: Uropodina: Trigonuropodidae). Zootaxa 1856: 55-66.

MahunKa, S. 2007. Taxonomical and faunistical studies on oribatids collected in Kenya (Acari: Oribatida) I. Acta Zoologica Academiae Scientiarum Hungaricae 53 (1): 51-74.

ManunKa, S. 2008. A new genus and some other data of Oribatids from Thailand (Acari: Oribatida). Acta Zoologica Academiae Scientiarum Hungaricae 54 (2): 125-150.

VÁzquez, M.M. \& H. Klompen. 2007. New records of Uropodina mites from México, Guatemala, Belize and Costa Rica. Dugesiana 14 (1): 27-37.

Wisniewski, J. 1993a. Gangsystematik der Parasitiformes Teil 549. Die Uropodiden der Erde nach Zoogeographischen Regionen und Subregionen geordnet (Mit Angabe der Lande). Acarologie Schriftenreihe für Vergleichende Milbenkunde 40: 221-291.

WisNiEWsKI, J. 1993b. Alphabetisches Verzeichnis der Uropodiden (Gattungen, Arten, Synonyma). Acarologie Schriftenreihe für Vergleichende Milbenkunde 40: 371-429.

Wisniewski, J. \& W. Hirschmann. 1993. Gangsystematik der Parasitiformes Teil 548. Katalog der Ganggattungen, Untergattungen, Gruppen und Arten der Uropodiden der Erde. Acarologie. Schriftenreihe für Vergleichende Milbenkunde 40: 1-220.

Zicsi, A. \& Cs. Csuzdi. 2008. Report on the soil-zoological expeditions to Ecuador and Colombia between 1986-1993. I. list of localities and habitats of "Berlese" samples. Opuscula Zoologica Budapest 37: 71-88.

Submitted: 01.Vl.2009; Accepted: 22.I.2010.

Editorial responsibility: Gabriel Mejdalani 